\title{
Quantification of methane emission rates from coal mine ventilation shafts using airborne remote sensing data
}

\author{
T. Krings ${ }^{1}$, K. Gerilowski ${ }^{1}$, M. Buchwitz ${ }^{1}$, J. Hartmann ${ }^{2}$, T. Sachs ${ }^{3}$, J. Erzinger ${ }^{3}$, J. P. Burrows ${ }^{1}$, and H. Bovensmann ${ }^{1}$ \\ ${ }^{1}$ University of Bremen, Institute of Environmental Physics, P.O. Box 330440, 28334 Bremen, Germany \\ ${ }^{2}$ Alfred Wegener Institute for Polar and Marine Research, Am Handelshafen 12, 27570 Bremerhaven, Germany \\ ${ }^{3}$ Helmholtz Centre Potsdam - GFZ German Research Centre for Geosciences, Telegrafenberg, 14473 Potsdam, Germany \\ Correspondence to: T. Krings (thomas.krings@iup.physik.uni-bremen.de)
}

Received: 24 September 2012 - Published in Atmos. Meas. Tech. Discuss.: 4 October 2012

Revised: 20 December 2012 - Accepted: 21 December 2012 - Published: 30 January 2013

\begin{abstract}
The quantification of emissions of the greenhouse gas methane is essential for attributing the roles of anthropogenic activity and natural phenomena in global climate change. Our current measurement systems and networks, whilst having improved during the last decades, are deficient in many respects. For example, the emissions from localised and point sources such as landfills or fossil fuel exploration sites are not readily assessed. A tool developed to better understand point sources of the greenhouse gases carbon dioxide and methane is the optical remote sensing instrument MAMAP (Methane airborne MAPper), operated from aircraft. After a recent instrument modification, retrievals of the column-averaged dry air mole fractions for methane $\mathrm{XCH}_{4}$ (or for carbon dioxide $\mathrm{XCO}_{2}$ ) derived from MAMAP data have a precision of about $0.4 \%$ or better and thus can be used to infer emission rate estimates using an optimal estimation inverse Gaussian plume model or a simple integral approach.

$\mathrm{CH}_{4}$ emissions from two coal mine ventilation shafts in western Germany surveyed during the AIRMETH 2011 measurement campaign are used as examples to demonstrate and assess the value of MAMAP data for quantifying $\mathrm{CH}_{4}$ from point sources. While the knowledge of the wind is an important input parameter in the retrieval of emissions from point sources and is generally extracted from models, additional information from a turbulence probe operated on-board the same aircraft was utilised to enhance the quality of the emission estimates. Although flight patterns were optimised for remote sensing measurements, data from an in situ analyser for $\mathrm{CH}_{4}$ were found to be in good agreement with retrieved dry columns of $\mathrm{CH}_{4}$ from MAMAP and could be used to
\end{abstract}

investigate and refine underlying assumptions for the inversion procedures.

With respect to the total emissions of the mine at the time of the overflight, the inferred emission rate of $50.4 \mathrm{kt} \mathrm{CH}_{4} \mathrm{yr}^{-1}$ has a difference of less than $1 \%$ compared to officially reported values by the mine operators, while the uncertainty, which reflects variability of the sources and conditions as well as random and systematic errors, is about $\pm 13.5 \%$.

\section{Introduction}

Methane $\left(\mathrm{CH}_{4}\right)$ is one of the most important anthropogenic greenhouse gases, having a global warming potential that is more than 20 times higher than that for $\mathrm{CO}_{2}$ on a 100 yr time horizon (Forster et al., 2007; Shindell et al., 2009). Forty percent of the total emissions originate from localised or point sources, such as landfills and fossil fuel production sites (Wuebbles and Hayhoe, 2002). Often these sources cannot be adequately or sufficiently monitored by existing in situ and remote sensing instruments. For example, during an intercomparison between various existing in situ and remote sensing methods, Babilotte et al. (2010) find $\mathrm{CH}_{4}$ emission rate estimates for a particular landfill that differ by an order of magnitude. Existing satellite techniques do not have sufficient spatial resolution to detect such localised sources (compare, for example, Gerilowski et al., 2011, and references therein). However, a new generation of potential satellite instruments such as CarbonSat (Bovensmann et al., 2010) is currently being developed. 
The Methane Airborne Mapper (MAMAP) instrument is a passive remote sensing instrument designed for airborne applications to retrieve columns of $\mathrm{CH}_{4}$ and $\mathrm{CO}_{2}$. This instrument is designed to address the existing observational gap and at the same time serve as a proof of concept for future greenhouse gas satellite missions. It builds on the heritage of the SCIAMACHY project, which has demonstrated that $X \mathrm{CH}_{4}$ and $X \mathrm{XO}_{2}$ can be measured and retrieved from space (Schneising et al., 2011; Burrows et al., 1995; Bovensmann et al., 1999, and references therein). Its shortwave infrared spectrometer measures in the wavelength region of $1590 \mathrm{~nm}$ to $1690 \mathrm{~nm}$ with a resolution of $0.82 \mathrm{~nm}$ FWHM (full width at half maximum) covering $\mathrm{CH}_{4}$ and $\mathrm{CO}_{2}$ absorption bands. A detailed description can be found in Gerilowski et al. (2011). The retrieval algorithm is presented and discussed by Krings et al. (2011) including description and validation of methods to use MAMAP total column data to estimate $\mathrm{CO}_{2}$ emission rates for different coal-fired power plants.

In this contribution, the application of MAMAP to infer reliable $\mathrm{CH}_{4}$ emission rate estimates is demonstrated using the example of two coal mine ventilation shafts from a German anthracite coal mine, surveyed with the MAMAP instrument on 4 June 2011 as part of the AIRMETH 2011 campaign. The experiments were performed using the Alfred Wegener Institute DC-3T airborne research platform Polar 5. Of the basic sensor suite, particularly the AIMMS-20 (Aircraft Integrated Meteorological Measurement System) turbulence probe added as compared to previous MAMAP campaigns is of interest for the retrieval of MAMAP $\mathrm{XCH}_{4}$, because it delivers independent wind information at $30 \mathrm{~Hz}$ temporal resolution. This enhances our knowledge of the wind provided from meteorological models. The study of local and regional methane sources was the focus of this campaign. In addition to the MAMAP instrument, the aircraft payload comprised a LGR Los Gatos Research Inc. RMT-200 fast $\mathrm{CH}_{4}$ in situ analyser. The analyser was equipped with an external pump to deliver fast in situ methane measurements with a temporal resolution of $10 \mathrm{~Hz}$ at flight altitude.

\section{Target description}

The RAG Anthrazit Ibbenbüren GmbH coal mine is located in western Germany close to the city of Ibbenbüren (see Fig. 1). Here, anthracite coal with a high degree of coalification and a comparably low content of volatile components $(5-6 \%$, http://www.dsk-anthrazit-ibbenbueren.de/) is extracted. In comparison to other coal fields, the Ibbenbüren anthracite has a rather high content of mine gas (originally $21 \mathrm{~m}^{3} \mathrm{t}^{-1}$ ). This is attributed to a warming of rocks in geologically young times presumably resulting from its larger depth compared to coal seams of the Ruhr area (EnergieAgentur.NRW, 2009).

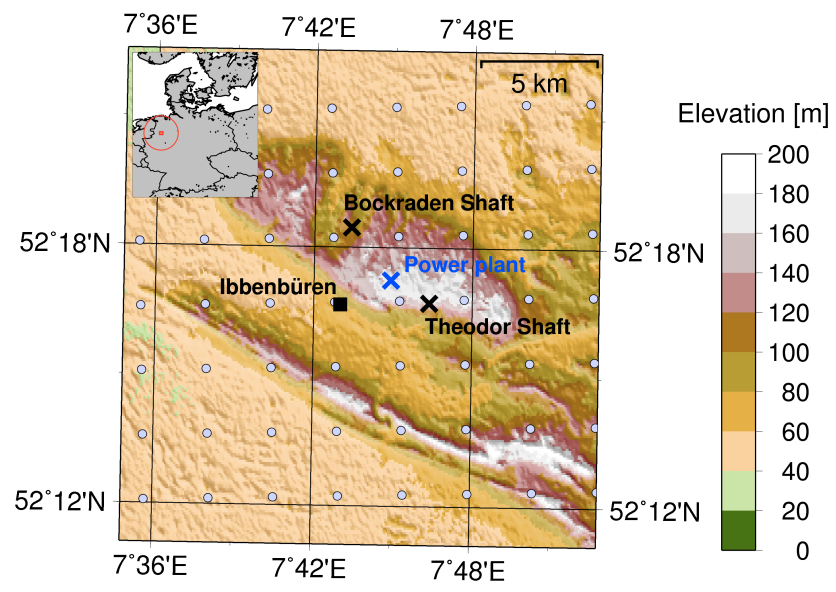

Fig. 1. Map showing the location of the anthracite mine and the corresponding ventilation shafts that release $\mathrm{CH}_{4}$ to the atmosphere, Bockraden Shaft and Theodor Shaft. The shafts are close to the city of Ibbenbüren. Light blue circles denote the COSMO-DE model data grid. (Map in UTM projection. Topographic data have been obtained from the Shuttle Radar Topography Mission (SRTM) version 2.1 (http://dds.cr.usgs.gov/srtm/version2_1/), a collaborative effort from NASA, NGA as well as the German and Italian Space Agencies).

Mine gas is naturally produced during the slow transformation of plant matter to coal. It generally consists of methane, carbon dioxide and nitrogen. Additionally, also hydrogen, water vapour, ethane $\left(\mathrm{C}_{2} \mathrm{H}_{6}\right)$ and hydrogen sulfide $\left(\mathrm{H}_{2} \mathrm{~S}\right)$ can occur (EnergieAgentur.NRW, 2009). For coal seams in the German state of North Rhine-Westphalia, the gas content per ton coal is typically $0-22 \mathrm{~m}^{3}$. In case of an active mine, the composition by volume is about $25-60 \% \mathrm{CH}_{4}$ (coal seam methane, CSM), $1-6 \% \mathrm{CO}_{2}, 0.1-0.4 \% \mathrm{CO}, 7-$ $17 \% \mathrm{O}_{2}, 4-40 \% \mathrm{~N}_{2}$ and traces of higher hydrocarbon compounds (EnergieAgentur.NRW, 2009).

German safety regulations require that $\mathrm{CH}_{4}$ mixing ratios in mines remain below 1-1.5\% ( $\$ 35 \mathrm{BVOSt}$, "Bergverordnung für die Steinkohlenbergwerke (BVOSt), vom 10. Januar 2000, in der Fassung vom 1.5.2001.”), because methane is explosive in air mixing ratios of $4.4-16.5 \%(1013.25 \mathrm{hPa}$, $20^{\circ} \mathrm{C}$ ) (EnergieAgentur.NRW, 2009). As a consequence, mine gas has to be extracted using ventilation and direct suction systems (ventilation air methane, VAM). Due to the variability of mine gas in different active mining areas of the same mine, gas production can vary by an order of magnitude during the year. Additionally, the gas production varies during the course of the week. It is generally highest on Friday evening and lowest on Monday morning, because there is often no coal extraction during weekends and gas production in active mines is tightly linked to cutting of fresh coal (EnergieAgentur.NRW, 2009). However, an abandoned coal mine continues to emit $\mathrm{CH}_{4}$ with a half-life of $10-20 \mathrm{yr}$ (Dones et al., 2007, and references therein). 
In case of the active Ibbenbüren coal mine, the mine gas is released through two ventilation shafts about $4.5 \mathrm{~km}$ apart: the Theodor Shaft (Theodorschacht) and the Bockraden Shaft (Bockradener Schacht). Each ventilation shaft is approximately $15 \mathrm{~m}$ high and has a diameter of about $7 \mathrm{~m}$. Potential co-release of $\mathrm{CO}_{2}$ does not hamper $\mathrm{CH}_{4}$ measurements using MAMAP due to the by far higher sensitivity for $\mathrm{CH}_{4}$ in terms of mass (Krings et al., 2011) and the low content of $\mathrm{CO}_{2}$. There is a small coal-fired power plant about half way between the shafts. It produces about $800 \mathrm{MW}$ of power (RWE POWER AG, http://www.rwe.com/) and in 2010 emitted $4.97 \mathrm{MtCO}_{2}$ according to the E-PRTR (European Pollutant Release and Transfer Register, http://prtr. ec.europa.eu/). However, its $\mathrm{CO}_{2}$ plume is not significantly interfering with the methane emissions due to the spatial separation.

The area around the ventilation shafts is characterised by hilly topography that is shown strongly exaggerated in Fig. 1. According to the SRTM data, Theodor Shaft is located at an altitude of about $150 \mathrm{~m}$, Bockraden Shaft at about $106 \mathrm{~m}$ and the power plant at about $174 \mathrm{~m}$ a.s.l.

The overflight on 4 June 2011 took place at 09:0010:20 UTC during clear sky and sunny conditions. For the target area, local time was UTC $+2 \mathrm{~h}$.

\section{Measurement data}

The column-averaged dry air mole fractions $\mathrm{XCH}_{4}$ were retrieved using the WFM-DOAS algorithm described in Krings et al. (2011). The background profiles determining the linearisation point are based on the US standard profile shifted to actual concentrations. For $\mathrm{CO}_{2}$, a constant background profile of $390 \mathrm{ppm} X \mathrm{XO}_{2}$ was assumed. For $\mathrm{CH}_{4}$, the profile has been updated to $1757 \mathrm{ppb} \mathrm{XCH}_{4}$ (with a surface concentration of $1840 \mathrm{ppb}$ ) based on the median value of the airborne in situ measurements, which was about $1840 \mathrm{ppb}$ in the boundary layer for this region. The median is generally more robust in presence of outliers, which in this case are the systematic enhancements in the methane plume. The same methane profile has been used as background for the inversion process. Generally, in cases where no airborne in situ data on the background column are available, the regional background can be determined using satellite or model data as well as information from surface networks.

MAMAP data with a relative detector filling of about 5$85 \%$ of the full well capacity have been selected to avoid low signals or signals close to saturation. For the reference radiative transfer model computed with SCIATRAN (Rozanov et al., 2005), an OPAC background aerosol scenario (Hess et al., 1998), an aircraft altitude of $1100 \mathrm{~m}$, a mean solar zenith angle of $36^{\circ}$ and an average surface elevation of $0.1 \mathrm{~km}$ have been assumed. In this configuration, the conversion factor to correct for the altitude sensitivity effect (see Krings et al., 2011) is about $k=0.555$.
Each measurement consists of 10 readouts having a total integration time of about $1 \mathrm{~s}$ and was selected to compute its average provided more than half of the measurements passed the fit quality and signal threshold criteria as well as other potential filter criteria such as the altitude filter (see below).

As a consequence of an instrument modification reducing pseudo-noise introduced by inhomogeneous scenes as proposed by Gerilowski et al. (2011), the fit quality is significantly improved compared to previous MAMAP data published by Gerilowski et al. (2011) and Krings et al. (2011) and the inversion result is generally not strongly dependent on a quality filter based on the root mean square (RMS) between model and fit. Figure 2 shows the fit quality of the retrieval algorithm before any filters. Compared to data recorded with the old instrument configuration presented by Krings et al. (2011) where $25 \%$ of the data were rejected, this is a significant improvement. Only few spectra have a low fit quality, of which $93 \%$ exhibit too low signals and are subsequently rejected by the abovementioned signal filter. The standard deviation of the $\mathrm{XCH}_{4}$ data before reaching the measurement area and after leaving the measurement area is below $0.4 \%$. This is an improvement of about a factor of 2.5 compared to the precision obtained previously. In the measurement area, the standard deviation naturally is larger because of real atmospheric variations and resulting from flight manoeuvres.

To accommodate for aircraft aperture and mechanical setup, a telescope with a focal length of $F \approx 150 \mathrm{~mm}(f$ number of $f / 3.9$ ) has been installed. For an aircraft altitude of about $1100 \mathrm{~m}$, a ground speed of $200 \mathrm{kmh}^{-1}$ and an integration time of about $1 \mathrm{~s}$ for 10 co-added measurements, the ground scene is approximately $40 \mathrm{~m} \times 90 \mathrm{~m}$ (cross track $\times$ along track).

For the quantitative analysis of the data, the RMS filter as well as any smoothing has been disabled. An altitude filter (allowing 1000-1200 m flight altitude) has been added to avoid errors for low flight tracks that intersect the vertical plume extension and that were meant for gathering in situ data. In these cases, methane molecules above the aircraft would not be correctly attributed by the MAMAP retrieval.

Figure 3 (left) shows $X \mathrm{CH}_{4}\left(\mathrm{CO}_{2}\right)$ obtained with the $\mathrm{CO}_{2}$ proxy method over the target area. For the proxy method, which is a relative method, the column-averaged mole fractions, $\mathrm{XCH}_{4}\left(\mathrm{CO}_{2}\right)$, are computed from the $\mathrm{CH}_{4} / \mathrm{CO}_{2}$ column ratio and the altitude conversion factor, where $\mathrm{CH}_{4}$ and $\mathrm{CO}_{2}$ are the retrieved columns (compare Krings et al., 2011, for details). The proxy method offers the advantage of accounting for light path variations that may occur, for example, in the presence of aerosols or sub-visual cirrus. These variations are similar for observations that are spectrally close to one another and cancel to a large extent for their ratios. This method has been used also for satellite remote sensing applications (compare, for example, Frankenberg et al., 2005; Schneising et al., 2009). A quantitative assessment of the proxy method using MAMAP data can be 


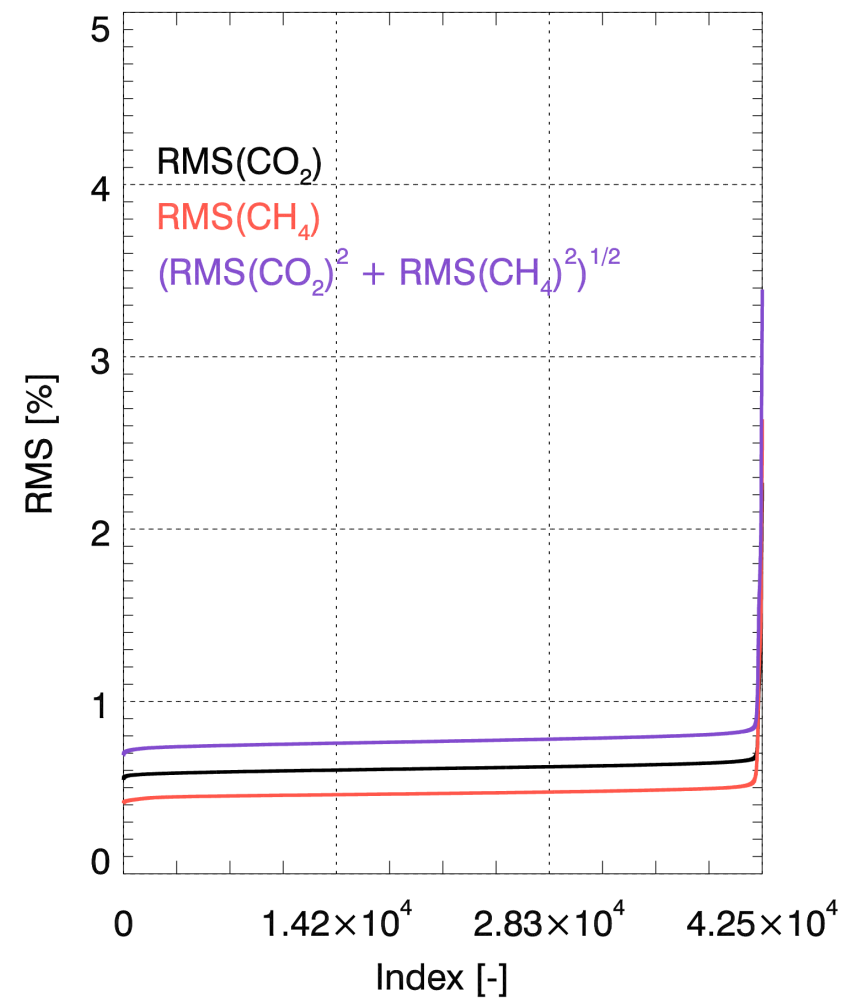

Fig. 2. Fit quality of the measurements ordered by the root-meansquare value of the relative differences between measurement and model after the fit.

found in Krings et al. (2011). The $\mathrm{XCH}_{4}\left(\mathrm{CO}_{2}\right)$ data were re-normalized to account for a potential, constant bias in the assumed $\mathrm{XCO}_{2}$ background column. Clearly visible are the two $\mathrm{CH}_{4}$ plumes being dispersed in downwind direction and with a stronger emission rate for the southern ventilation shaft (Theodor Shaft). Furthermore, a small negative anomaly can be observed originating at the power plant's location. This is caused by the increased $\mathrm{CO}_{2}$ in the power plant's flue gas that appears in the $\mathrm{XCH}_{4}\left(\mathrm{CO}_{2}\right)$ as a methane depletion as the $\mathrm{CH}_{4}$ to $\mathrm{CO}_{2}$ column ratio is lower than background. Other significant variations of $X_{\mathrm{CO}_{2}}$ are not to be expected for the generally well-mixed $\mathrm{CO}_{2}$ in the small area of interest. This assumption is further supported by the fact that $X \mathrm{CH}_{4}\left(\mathrm{CO}_{2}\right)$ exhibits small variability outside the plume areas. The $\mathrm{CH}_{4}$ plume from the northern ventilation shaft (Bockraden Shaft) exhibits a broken and discontinuous appearance, which indicates unstable atmospheric conditions that may be further enhanced by topography effects. In addition, the single gas columns of $\mathrm{CH}_{4}$ and $\mathrm{CO}_{2}$ are qualitatively displayed in Fig. 3 (right). They do not represent dry air mole fractions and are shown at a different scale. The methane plume can be clearly observed already in the single gas $\mathrm{CH}_{4}$ data. Furthermore, $\mathrm{CH}_{4}$ and $\mathrm{CO}_{2}$ generally suffer from systematic errors at the same locations that cancel for the proxy method.
Figure 3 shows additional areas with apparently systematic depletion in $\mathrm{XCH}_{4}\left(\mathrm{CO}_{2}\right)$. This does not seem to originate from the proxy method (potentially increased $\mathrm{CO}_{2}$ ) but arises from the $\mathrm{CH}_{4}$ spectral region directly. Data at the anomalies have only a slightly decreased fit quality, but it turns out that these features spatially coincide with bankings of excavated material from the mine. This is confirmed by aerial imagery (Fig. 4) and by the pointing camera of the MAMAP instrument. Since no plume is obvious downwind of these deposits, this is likely an effect caused by surface properties, i.e. surface spectral reflectance, and not related to depletion in $\mathrm{CH}_{4}$ (or increased $\mathrm{CO}_{2}$ ).

A possible explanation for this behaviour could be systematic effects that become more relevant for decreased signal strength over ground scenes with reduced surface reflectance such as the excavation material.

Potentially, also fluorescence, which is the emission of electromagnetic radiation at wavelengths different from the excitation wavelengths, may contribute to these erroneous signals. Minerals are generally known to exhibit fluorescence (Gaft et al., 2005). This would result in an additive component to the light intensity that cannot be accounted for by the polynomial for the logarithmic fit. A synthetic retrieval confirms that, in case of low surface reflectance, an additive component of about $+2 \%$ of the total signal can lead to a spurious decrease in $\mathrm{XCH}_{4}\left(\mathrm{CO}_{2}\right)$, which is comparable to the observed decrease over the excavated material. Since these areas are not located close to the dispersion plume of the ventilation shafts, this matter has been disregarded for further data processing. However, the precise origin of the above effect requires further investigation with additional measurements.

\section{Wind data}

Similar to Krings et al. (2011), wind information for the air layers of interest has been obtained from the routine analysis of the numerical weather prediction model COSMO-DE operated by the German Weather Service (DWD) based on the COSMO model (Doms, 2011). Model data have been obtained that are given on model levels granting a horizontal resolution of $2.8 \mathrm{~km} \times 2.8 \mathrm{~km}$ and a vertical resolution of about $20 \mathrm{~m}$ near ground and $150 \mathrm{~m}$ at $1000 \mathrm{~m}$ altitude. These coordinates are terrain following. The lowest model layer (number 50) is approximately $10 \mathrm{~m}$ above ground. For the model grid point west of Theodor Shaft, surface elevation and model layer centre altitudes are exemplarily given in Table 1.

Wind fields for model layers 50, 45 and 40 for UTC times 09:00, 10:00 and 11:00 are shown in Fig. 5. The model wind is rather uniform in speed and direction with no significant influence of the topography at model resolution. Wind speed is increasing with altitude and the direction is turning clockwise. This is to be expected as wind becomes geostrophic with decreasing surface friction due to the Coriolis force. 

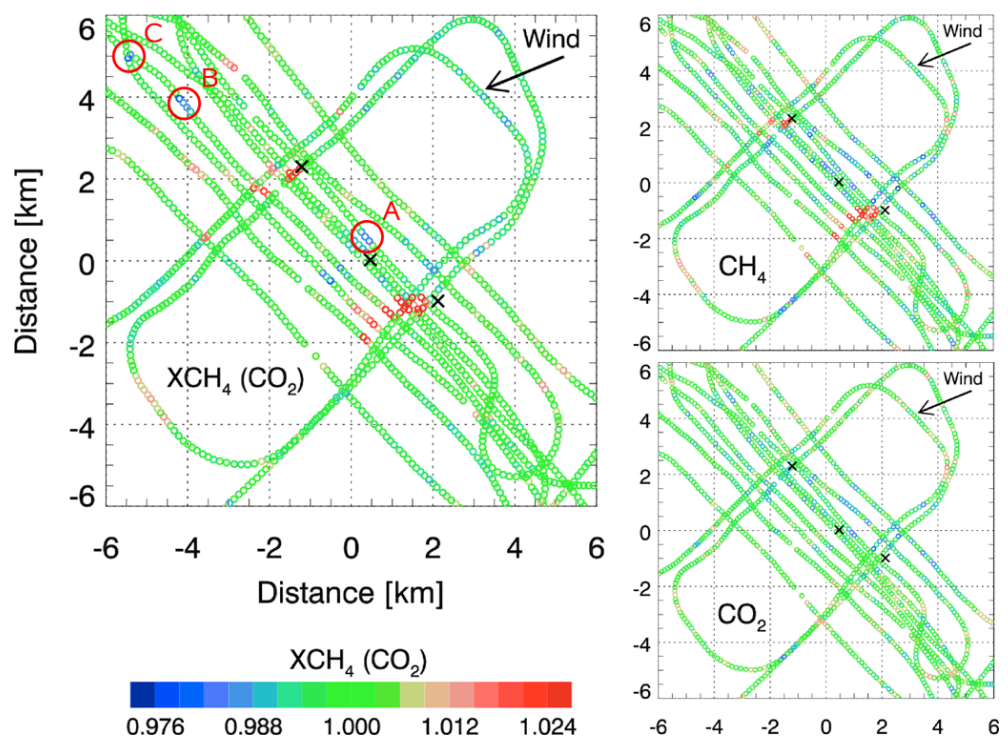

Fig. 3. Un-smoothed and not RMS-filtered MAMAP data. An altitude filter has been applied to obtain quantitatively meaningful results for $\mathrm{XCH}_{4}\left(\mathrm{CO}_{2}\right)$. Data have been normalised to regional background as observed during the flight. Upper and lower right show additionally the $\mathrm{CH}_{4}$ and $\mathrm{CO}_{2}$ single columns. Note that they do not represent dry air mole fractions and have a different scale than $X \mathrm{CH}_{4}\left(\mathrm{CO}_{2}\right)$. The encircled areas $\mathrm{A}, \mathrm{B}$ and $\mathrm{C}$ denote areas with $\mathrm{XCH}_{4}$ anomalies described in the main text.

A

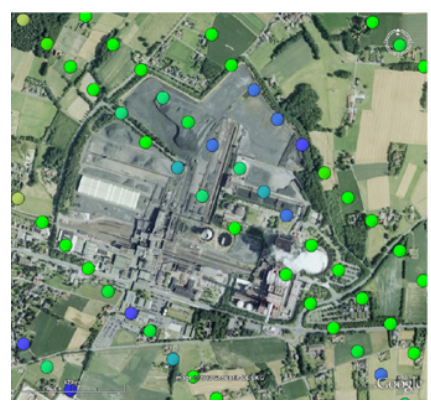

B

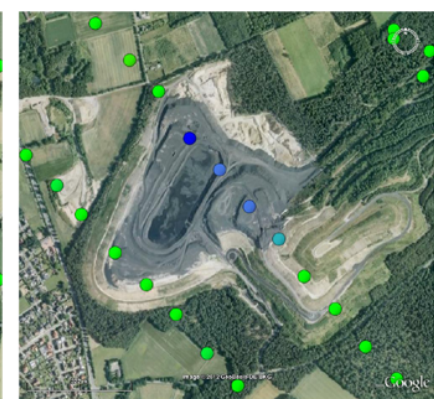

C

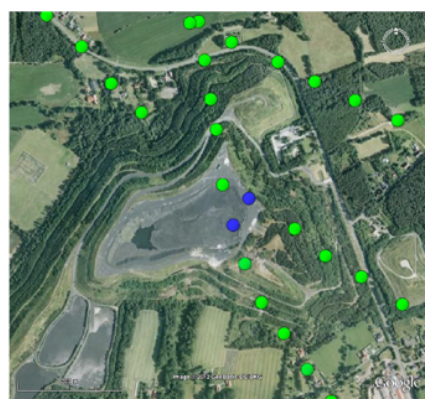

Fig. 4. MAMAP data superimposed on Google Earth aerial imagery of anomaly locations. As can be seen, low $X \mathrm{CH}_{4}\left(\mathrm{CO}_{2}\right)(\mathrm{blue}$ circles) correlates with areas of excavated material (grey). Panels (A), (B) and (C) denote the anomalies marked in Fig. 3. Data points denote the centre position of measured areas and are not to scale with observed ground scenes, which are about twice as large and of rectangular shape.

Later, the difference between surface and aloft decreases as the mixed layer grows.

The evolution of the mixed layer can be better seen from profiles at the two nearest neighbours of Theodor Shaft and Bockraden Shaft, respectively (Fig. 6). The mixed layer grows from about $350 \mathrm{~m}$ thickness at 08:00 UTC to about $1100 \mathrm{~m}$ at 11:00 UTC characterised by the step in wind speed and direction at the transition to the free troposphere. The upper boundary of the mixed layer acts as a lid, and gas plumes from sources within this layer are not likely to extend beyond it. In close vicinity to Theodor Shaft, wind speed ranges from $6 \mathrm{~m} \mathrm{~s}^{-1}$ to $9 \mathrm{~m} \mathrm{~s}^{-1}$ for the mixed layer and wind direction from $55^{\circ}$ to $65^{\circ}$, only slowly varying with time apart from changes introduced by the mixed layer evolution. For Bockraden Shaft, wind speeds are slightly lower ranging from
$5 \mathrm{~m} \mathrm{~s}^{-1}$ to $9 \mathrm{~m} \mathrm{~s}^{-1}$ in the mixed layer with wind directions similar to Theodor Shaft.

All wind data from the COSMO-DE model for the measurement area are shown in Fig. 7. Variations in wind speed across the area are about $\pm 1 \mathrm{~m} \mathrm{~s}^{-1}$ at 09:00 UTC decreasing to about $\pm 0.5 \mathrm{~m} \mathrm{~s}^{-1}$ at 11:00 UTC. The great scatter in wind speed at about $450 \mathrm{~m}$ altitude across the area at 09:00 UTC is due to the different depth of the mixed layer for different model locations mainly depending on surface elevation. Wind direction varies by about $\pm 5^{\circ}$ and shows the same scattering at the mixed layer boundary.

To compare the COSMO-DE model data with wind information acquired at flight altitude over the measurement area using the AIMMS-20 turbulence probe, model data from the whole area have been fitted by a sixth-order polynomial for 
Table 1. Model layer altitudes and corresponding altitudes of layer centres above ground at the model grid position east of Theodor Shaft $\left(52.2794^{\circ} \mathrm{N}, 7.7540^{\circ} \mathrm{E}\right)$. The first line of the table refers to the surface elevation.

\begin{tabular}{lrrrrr}
\hline & \multicolumn{2}{c}{ Altitude a.s.l. $(\mathrm{m})$} & & \multicolumn{2}{c}{ Altitude above ground $(\mathrm{m})$} \\
\cline { 2 - 3 } \cline { 5 - 6 } Layer & Layer centre & Layer boundary & & Layer centre & Layer boundary \\
\hline 50 & 124.4 & 114.5 & & 9.9 & 0.0 \\
49 & 149.9 & 134.3 & & 35.4 & 19.8 \\
48 & 186.8 & 165.4 & & 72.3 & 50.9 \\
47 & 235.6 & 208.2 & & 121.1 & 93.7 \\
46 & 296.6 & 263.0 & & 182.1 & 148.5 \\
45 & 370.1 & 330.2 & & 255.6 & 215.7 \\
44 & 456.6 & 410.1 & & 342.1 & 295.6 \\
43 & 556.2 & 503.1 & & 441.7 & 388.6 \\
42 & 669.6 & 609.4 & & 555.1 & 494.9 \\
41 & 796.8 & 729.7 & & 682.3 & 615.2 \\
40 & 938.4 & 864.0 & & 823.9 & 749.5 \\
39 & 1094.7 & 1012.9 & & 980.2 & 898.4 \\
38 & 1266.0 & 1176.6 & & 1151.5 & 1062.1 \\
37 & 1452.7 & 1355.4 & & 1338.2 & 1240.9 \\
& & 1549.9 & & & 1435.4 \\
\hline
\end{tabular}

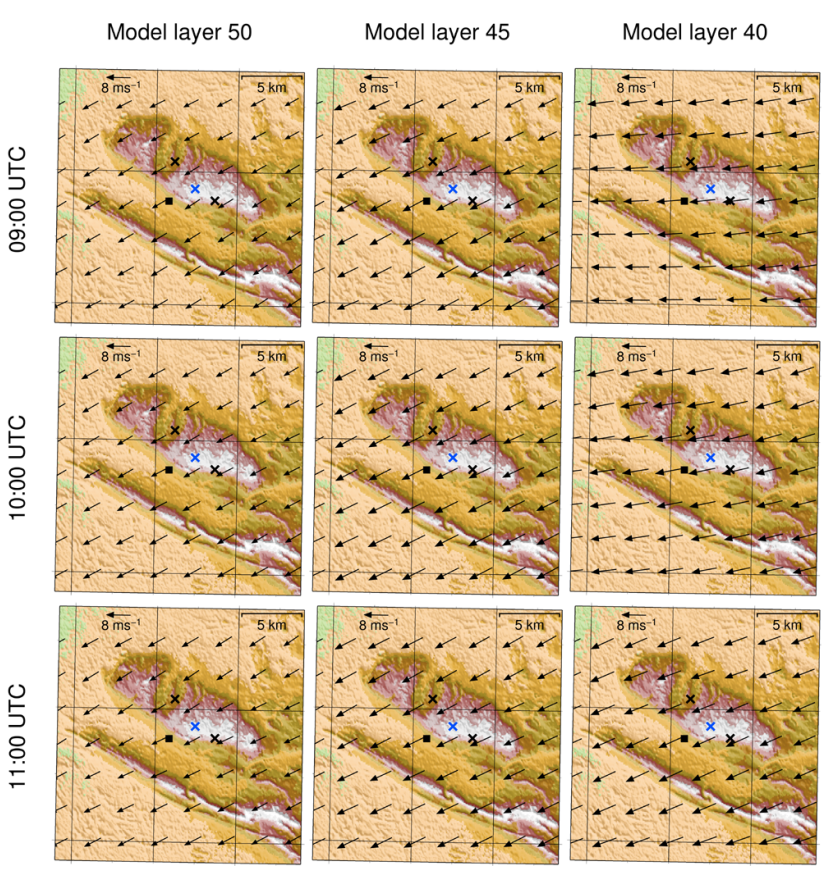

Fig. 5. Wind fields for different times (rows) and model layers (columns). Model layers 50, 45 and 40 thereby refer to altitudes above ground of approximately $10 \mathrm{~m}, 256 \mathrm{~m}$ and $824 \mathrm{~m}$, respectively, slightly depending on the surface elevation. Size of arrows is proportional to absolute wind speed.

altitudes covered by the overflight (Fig. 7). Wind components in north-south and east-west direction were fitted separately before wind speeds and directions were computed. The comparison between fitted model data and measurements from the turbulence probe is shown in Fig. 8a. The measurements have been smoothed by a 1000-point moving average representing approximately 1-min averages. Observation times of
A

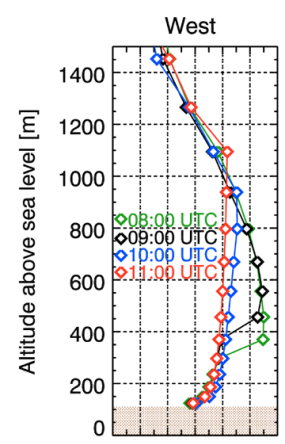

$2 \quad 4 \quad 6 \quad 8 \quad 10$ Wind speed $[\mathrm{m} / \mathrm{s}]$ Wind speed $[\mathrm{m} / \mathrm{s}]$ Wind direction $\left[^{\circ}\right]$ Wind direction $\left[^{\circ}\right]$

B Wind model Bockraden Shaft

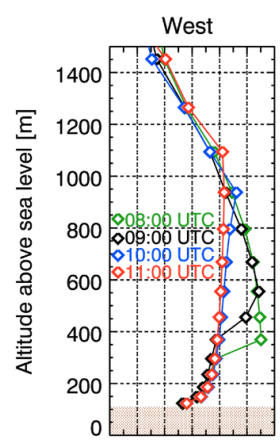

2446810

$\begin{array}{llllllllll}2 & 4 & 6 & 8 & 10 & 2 & 4 & 6 & 8 & 10\end{array}$
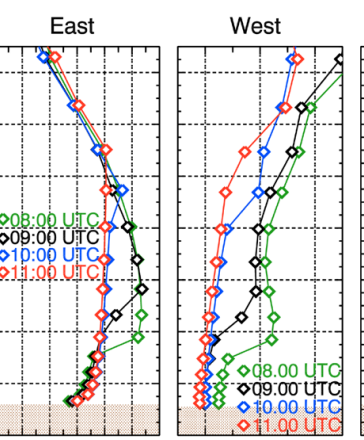

$6080 \quad 100$

Wind direction

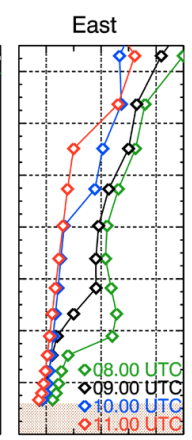

$\begin{array}{lll}60 & 80 \quad 100\end{array}$
Fig. 6. Panel (A): wind speed and direction for the model grid points west $\left(52.2794^{\circ} \mathrm{N}, 7.7540^{\circ} \mathrm{E}\right)$ and east $\left(52.2801^{\circ} \mathrm{N}, 7.7948^{\circ} \mathrm{E}\right)$ of the location of Theodor Shaft. Panel (B): same as panel (A) but for model grid points east $\left(52.3036^{\circ} \mathrm{N}, 7.7120^{\circ} \mathrm{E}\right)$ and west $\left(52.3043^{\circ} \mathrm{N}, 7.7528^{\circ} \mathrm{E}\right)$ of Bockraden Shaft. Local time was $\mathrm{UTC}+2 \mathrm{~h}$.

both measurement and model data are indicated by the colour scale.

The agreement for the altitudes of the remote sensing measurements $(1000-1200 \mathrm{~m})$ is good. The scatter for the measured data is higher than for the model data, which is given only on an hourly time scale. For lower altitudes, where the actual plume is located, the averaged model data seem to systematically overestimate the wind speed. For a more quantitative analysis, however, model and measurement have to be compared at the same location.

This can be accomplished using data from a descentascent profile reaching about $70 \mathrm{~m}$ above ground at the airport Münster/Osnabrück located approximately $17 \mathrm{~km}$ southsouthwest of Theodor Shaft which are compared to in situ data at the airport's weather station (EDDG) and the COSMO-DE model in Fig. 8. At this location, the systematic, negative bias of the model can be confirmed. Model data 
A

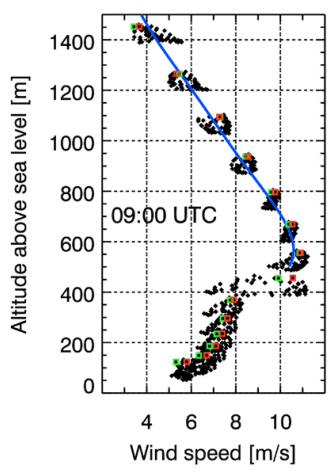

Model wind speed in target area

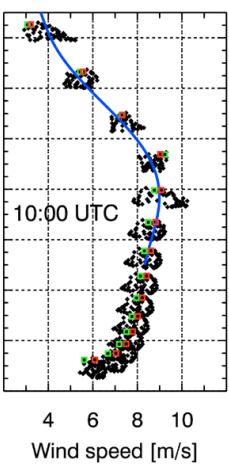

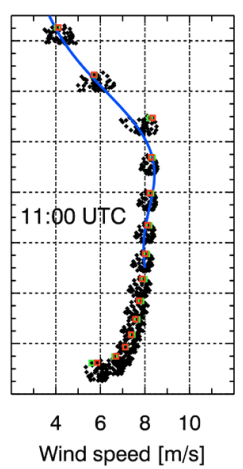

Wind speed $[\mathrm{m} / \mathrm{s}]$
B

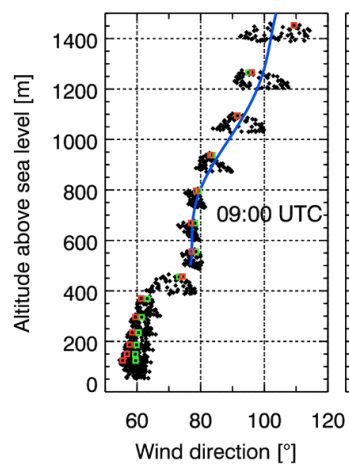

Model wind direction in target area

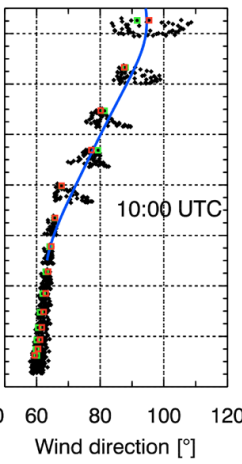

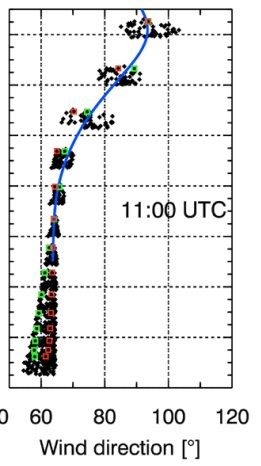

Fig. 7. Wind speed (panel A) and direction (panel B) from the COSMO-DE model throughout the measurement area as shown in Fig. 1. Red squares denote data from the location east of Theodor Shaft and green squares data east from Bockraden Shaft. The blue line indicates a sixth-order polynomial fit from about $500 \mathrm{~m}$ to $1500 \mathrm{~m}$ corresponding to flight altitudes during the survey.

at the airport's closest grid point at 11:00 UTC are on average about $0.7 \mathrm{~m} \mathrm{~s}^{-1}$ higher for the mixed layer taking into account the altitudes from the lowest measurement $(118 \mathrm{~m})$ to $600 \mathrm{~m}$. Considering the accuracy of the AIMMS-20 instrument for the horizontal wind of $0.5 \mathrm{~m} \mathrm{~s}^{-1}$ by specification (see, for example, Beswick et al., 2008) or better, this bias is significant. In situ wind data measured at $10 \mathrm{~m}$ above ground every 20-30 min also indicate an overestimation of wind speeds by the model. The data from the turbulence probe of the profile have therefore been used to calibrate the model applying a correction of $-0.7 \mathrm{~m} \mathrm{~s}^{-1}$. This correction is still within the error range of the wind model of about $0.9 \mathrm{~m} \mathrm{~s}^{-1}$ as given in Krings et al. (2011) for a specific example.

Wind directions between model and measurements agree within the uncertainties, although the weather station data indicate a high variability in wind direction of $\pm 20^{\circ}$ not captured by the model.
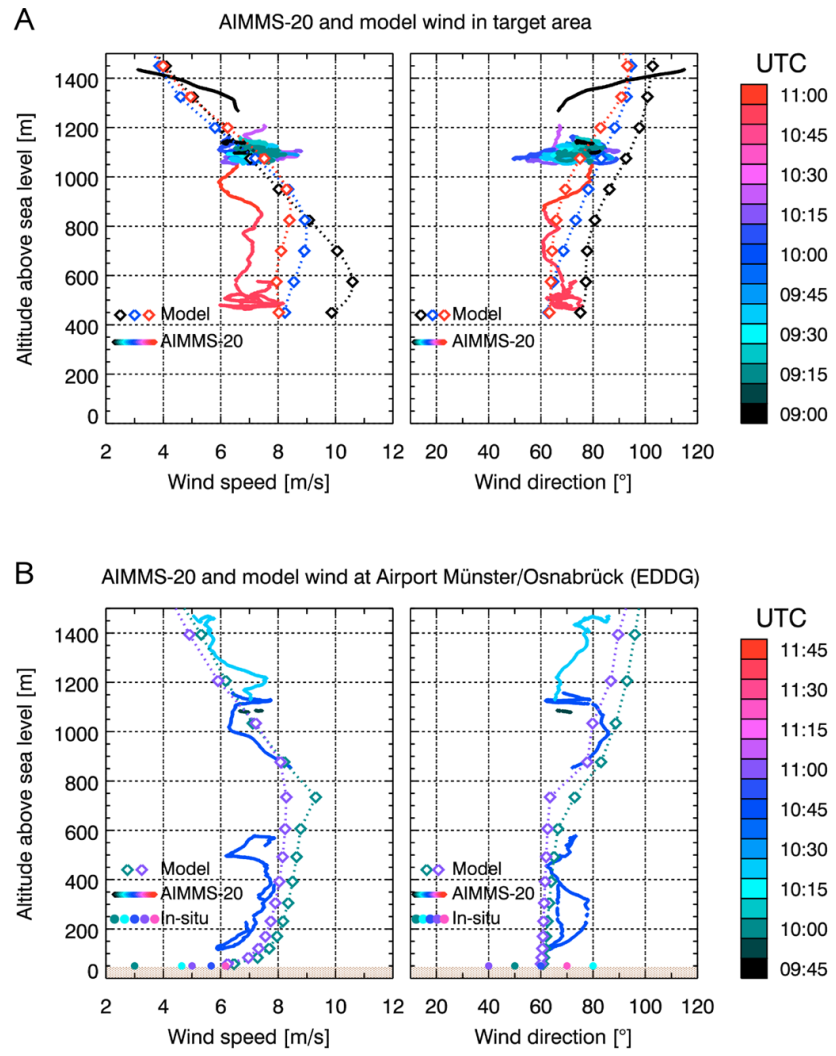

Fig. 8. Panel (A): comparison between mean model data (diamonds) for times 09:00, 10:00 and 11:00 UTC and AIMMS-20 turbulence probe wind data (thick line). The colour indicates the time according to the colour bar to the right. The left plot shows wind speed, the right plot wind direction. Panel (B): AIMMS-20 wind data from a descent-ascent profile at the airport Münster/Osnabrück and the surrounding area compared with model data at a grid point less than $100 \mathrm{~m}$ away from the airport $\left(52.1279^{\circ} \mathrm{N}, 7.6800^{\circ} \mathrm{E}\right)$. Additionally, in situ data from the weather station (EDDG) are shown. Times of measurements are according to the colour bar on the right. In situ data from the weather station at the airport Münster/Osnabrück (EDDG) have been obtained from Weather Underground (http: //www.wunderground.com/, last access: May 2012).

\subsection{Effective wind speed}

To compute an effective wind speed from the model data, it is assumed that the plume is approximately terrain following with respect to the vertical coordinate. This is, for example, a good approximation for smooth hills in neutral stability conditions (Hunt and Snyder, 1982). Additional turbulence is possible but has not been considered explicitly for this work. Part of it will be compensated by the stability fit, which cannot distinguish between diffusion and turbulent mixing on somewhat larger scales. The release height in case of Theodor Shaft was set to the surface elevation according to the SRTM model of $150 \mathrm{~m}$ plus the stack height of $15 \mathrm{~m}$. Since the COSMO-DE model elevation grid has a lower resolution, the model elevation at the Theodor Shaft location is 
A

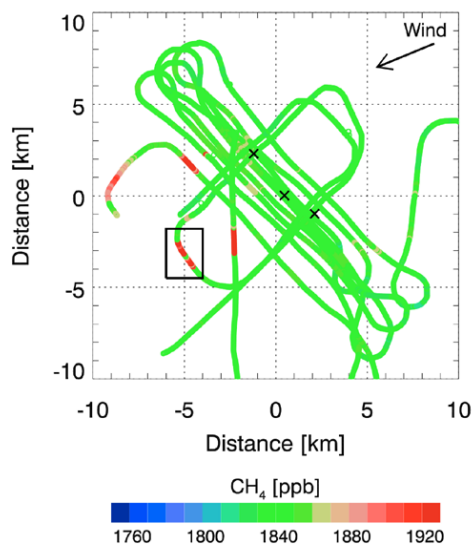

B

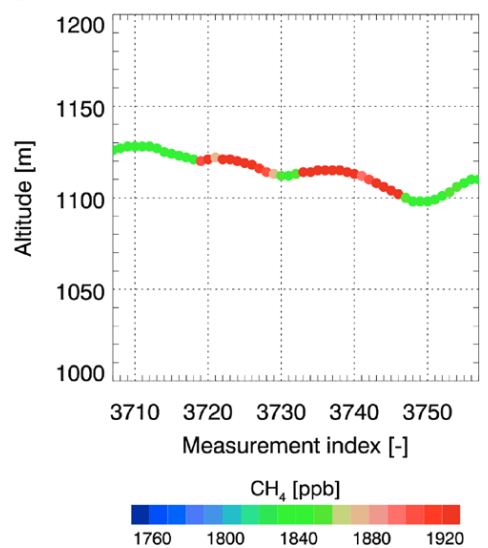

Fig. 9. Panel (A): methane data from the in situ probe averaged for $1 \mathrm{~s}$. Data from the furthest part of the plume as indicated by the black box are shown in panel $\mathbf{( B )}$.

only about $115 \mathrm{~m}$ when evaluating the nearest neighbour grid point.

The effective wind speed has been computed using the vertical wind profile of north-south and east-west components weighted by the concentration enhancement according to the modelled vertical dispersion at altitude $z$ (compare, for example, Pasquill, 1971; Beychok, 2005):

$C(z)=\frac{1}{\sigma_{z} \sqrt{2 \pi}}\left(e^{-\frac{1}{2}\left(\frac{z-h}{\sigma_{z}}\right)^{2}}+e^{-\frac{1}{2}\left(\frac{z+h}{\sigma_{z}}\right)^{2}}\right)$

with emission altitude $h$ and taking into account reflection off the ground. In case of Theodor Shaft, two effective wind speeds have been computed. The first corresponds to the close vicinity and the near part of the plume, taking into account the mean wind profile of the two nearest model grid locations (east and west of the ventilation shaft location). The vertical dispersion coefficient $\sigma_{z}$ has been computed according to (Martin, 1976)

$\sigma_{z}=c \cdot x^{d}+f$

with empirical constants $c, d$ and $f$ depending on the atmospheric stability class and assuming a mean distance from the shaft of $x=1 \mathrm{~km}$. The approximate stability class can be determined according to Turner (1970). Considering a mean solar zenith angle of about $36^{\circ}$ (moderate solar insolation) and a wind speed around $6 \mathrm{~m} \mathrm{~s}^{-1}$ (see Fig. 7), this results in stability classes D (neutral) or C (slightly unstable). This is confirmed in the inversion process (see below), which for the far and undisturbed plume results in a stability parameter $a$ that corresponds to a stability class between $\mathrm{C}$ and $\mathrm{D}$. Taking into account that topography may create an additional turbulent diffusion and considering that, for the far part of the plume, the in situ sensor picked up an average $\mathrm{CH}_{4}$ enhancement of about $80 \mathrm{ppb}$ (compare Fig. 9), which can only be modelled using stability class $C$ (see below), the slightly unstable case $\mathrm{C}$ has been used for computing the effective wind speed with corresponding parameters for the determination of $\sigma_{z}$ of $c=61.0, d=0.911$ and $f=0$.

For the near part of Theodor Shaft, this yields $\sigma_{z}=61 \mathrm{~m}$ and about $18 \%$ of the emitted $\mathrm{CH}_{4}$ is confined to the surface layer (layer 50 according to the COSMO-DE model). The next layers share $27 \%$ (layer 49), $30 \%$ (layer 48), $19 \%$ (layer 47), $5 \%$ (layer 46) and $0.3 \%$ (layer 45). Consequently, the corresponding plume height is approximately the upper boundary of layer 45 . Taking the altitude profile of the model grid point west of Theodor Shaft as reference, the plume presumably rises to about $296 \mathrm{~m}$ above ground. Taking the mean from 09:00 and 10:00 UTC, the effective wind speed for the near area of Theodor Shaft results in about $6.9 \mathrm{~m} \mathrm{~s}^{-1}$ and the mean wind direction in about $59.8^{\circ}$.

The second effective wind speed is evaluated for the far part of the plume in about $8 \mathrm{~km}$ distance from Theodor Shaft. Model wind profiles of 8 grid points throughout the plume extension have been considered taking into account the real distance to the source when evaluating the vertical dispersion including the dispersion coefficient $\sigma_{z}$ - except for one upwind profile east of Theodor Shaft, where the distance to the source was set to $0 \mathrm{~km}$. Model grid points have been selected so that no part of the plume is overly represented. The effective wind speed for the far part of the plume is then about $7.7 \mathrm{~m} \mathrm{~s}^{-1}$ and the wind direction about $63.1^{\circ}$. The vertical distribution at $8 \mathrm{~km}$ distance, according to these assumptions, is about $4 \%$ (layer 50), $6 \%$ (layer 49 ), $8 \%$ (layer 48 ), $10 \%$ (layer 47), $12 \%$ (layer 46), $13 \%$ (layer 45 and 44), $12 \%$ (layer 43), $9 \%$ (layer 42), $7 \%$ (layer 41 ), $4 \%$ (layer 40 ), $2 \%$ (layer 39) and less than $0.7 \%$ (layer 38).

The flight altitude corresponds to layer 39 with a share of the total column enhancement of $s=2 \%$. To compare with the in situ measurements, following assumptions are made: $100 \%$ of the released methane in a vertical column at about $8 \mathrm{~km}$ distance corresponds to about $\Delta_{\mathrm{tc}}=1.2 \%$ of the total background column as seen from MAMAP 
measurements, where the background column is $\mathrm{TC} \approx 3.75$. $10^{19} \mathrm{~mol} \mathrm{CH}_{4} \mathrm{~cm}^{-2}$; the air layer is $d \approx 160 \mathrm{~m}$ thick with an approximate pressure of about $p_{1}=900 \mathrm{hPa}$ and temperature of $T_{1}=288 \mathrm{~K}$. Assuming further air to be an ideal gas and using the Loschmidt number $N_{\mathrm{L}} \approx 2.7 \cdot 10^{19} \mathrm{molcm}^{-3}$ for the number of molecules at standard conditions $\left(p_{0}=\right.$ $1013.25 \mathrm{hPa}, T_{0}=273.15 \mathrm{~K}$ ), the expected in situ enhancement $\Delta_{\text {in-situ }}$ is

$\Delta_{\text {in-situ }}=\frac{s \Delta_{\mathrm{tc}} \mathrm{TC}}{N_{\mathrm{L}} \frac{p_{1} T_{0}}{p_{0} T_{1}} d} \approx 25 \mathrm{ppb}$,

which is in agreement with the measurements that showed about $80 \mathrm{ppb}$ increase, considering involved uncertainties and variability in vertical distribution. For comparison, stability class $\mathrm{D}$ (more stable than class $\mathrm{C}$ ) would yield a mole fraction increase in layer 39 that is too low to be measured (about $10^{11}$ times lower).

For the northern Bockraden Shaft, only the wind profile from the nearest model grid point has been taken into account. It is located about $870 \mathrm{~m}$ in downwind direction approximately half way between the ventilation shaft and the maximum, visible plume extension. For slightly unstable stability conditions, as before, and the measurement time 09:00-10:00 UTC, the effective wind speed amounts to about $6.4 \mathrm{~m} \mathrm{~s}^{-1}$ and the average wind direction is about $59.9^{\circ}$. The release height was taken to be the surface elevation according to the SRTM model plus the shaft height of $15 \mathrm{~m}$ resulting in $121 \mathrm{~m}$ a.s.l. This is about $7 \mathrm{~m}$ above ground according to the COSMO-DE surface elevation model.

\subsection{Calibration with wind measurements}

So far, information from the measured wind data has not been taken into account for the computation of the effective wind speed. Applying the wind speed calibration of $-0.7 \mathrm{~m} \mathrm{~s}^{-1}$ as presented in the previous section, the final effective wind speeds are $6.2 \mathrm{~m} \mathrm{~s}^{-1}$ for the near part of Theodor Shaft, $7.0 \mathrm{~m} \mathrm{~s}^{-1}$ for the far part and $5.7 \mathrm{~m} \mathrm{~s}^{-1}$ for Bockraden Shaft.

\section{Inversion}

Prior to the inversion, the data were rotated so that the wind direction points in positive $\mathrm{x}$-direction and subsequently gridded to regular boxes of $65 \mathrm{~m} \times 65 \mathrm{~m}$ covering approximately the same area as a MAMAP ground pixel. Subsequently, emission rates were inferred using an inverse Gaussian plume model and an integral approach.

\subsection{Gaussian plume inversion}

To invert for the $\mathrm{CH}_{4}$ emission rates, an inverse Gaussian plume model was applied using an optimal estimation scheme (Krings et al., 2011). The inversion is thereby based on the vertically integrated form
$V(x, y)=\frac{F}{\sqrt{2 \pi} \sigma_{y}(x) u} e^{-\frac{1}{2}\left(\frac{y}{\sigma_{y}(x)}\right)^{2}}$

where $V(x, y)$ denotes the retrieved vertical column of $\mathrm{CH}_{4}$, $\sigma_{y}$ the horizontal dispersion coefficient, $u$ the wind speed and $F$ the emission rate sought after. The a priori for the horizontal stability parameter $a$ according to (Martin, 1976)

$\sigma_{y}=a \cdot x^{0.894}$

has been set to $a=120 \pm 120$ only constraining the stability to the physically meaningful range. Having only one source, the inversion is statistically stable and does not need an additional constraint on the emission rate to prevent unrealistic results. Hence, no a priori information is needed for the emission rate. The wind direction has not been taken from the computation of effective wind speed and direction but from the measured MAMAP data directly. Although the COSMODE model shows similar wind directions for the part of the plume in the vicinity of Theodor Shaft and the total plume extension, this is not confirmed by the data. Close to the ventilation shaft, a wind direction of about $85^{\circ}$ was empirically found to best fit the data, whereas the far part alone represents a plume advected by wind coming from $71^{\circ}$.

The measurements in the close vicinity of Theodor Shaft apparently missed the plume, which is very narrow so close to the source. To avoid potential interference on the inversion of the near part of the plume, data from the first $300 \mathrm{~m}$ downwind have been excluded prior to the inversion. Similarly, data have been restricted to $\pm 1000 \mathrm{~m}$ in across wind direction to avoid the impact of other sources than the one under consideration. Finally, data further than $1800 \mathrm{~m}$ away from the ventilation shaft where the plume appears particularly rugged have been omitted. The selected rotated and gridded data are shown in Fig. 10a including the contour lines resulting from inferred emission rate and stability parameter.

The far part of the plume is subject to a different effective wind speed and direction. Hence, the plume (and integral) inversions of the near and far part have been conducted separately (Fig. 10b). The across wind limits have been set to $\pm 1800 \mathrm{~m}$ accounting for a wider dispersion further from the source.

As for the near part of Theodor Shaft, the data from Bockraden Shaft have been restricted to $\pm 1000 \mathrm{~m}$ in across wind direction. The wind direction is empirically determined to about $60.0^{\circ}$. In addition, data with a distance of more than $1.9 \mathrm{~km}$ from the source, where the plume starts to exhibit a very discontinuous appearance, have been rejected for the plume inversion (Fig. 11a).

\subsection{Gaussian integral inversion}

The Gaussian integral method is based on a budgeting approach of $\mathrm{CH}_{4}$ amounts being advected through boundaries build up by measurement tracks (Krings et al., 2011): 
A

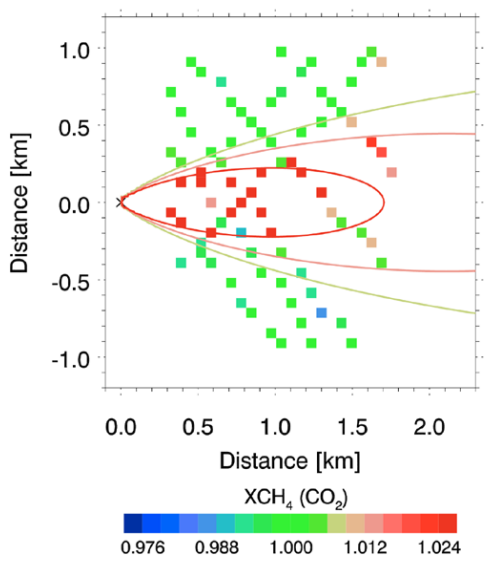

B

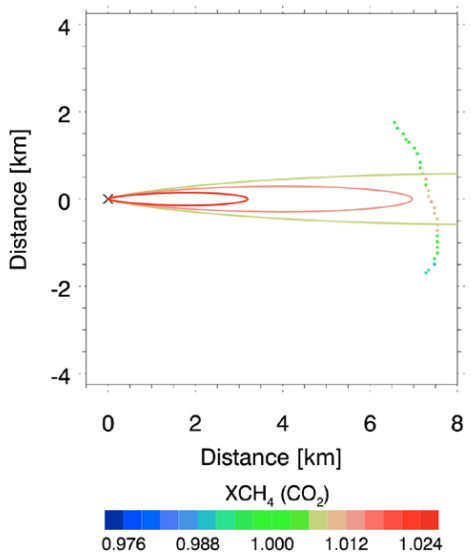

Fig. 10. Data used for the inversion of the near part of Theodor Shaft (panel A) and the far part (panel B). Contour lines indicate the result from the Gaussian plume model inversion.

A

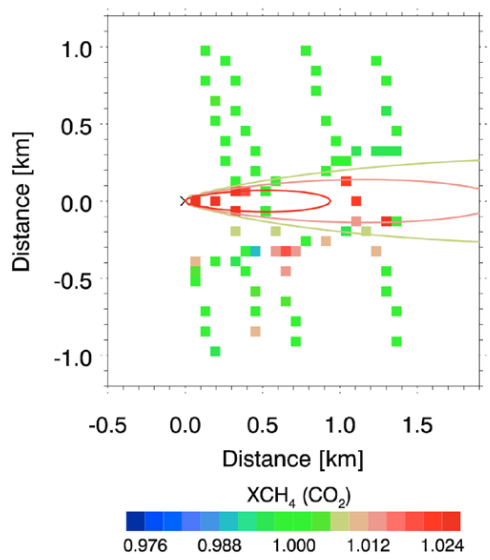

B

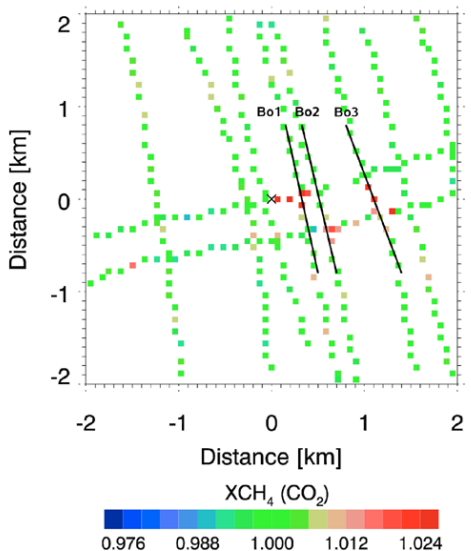

Fig. 11. Relevant data for the inversion of the emissions from Bockraden Shaft using the inverse Gaussian plume model (panel A) and the integral method (panel B). Contour lines (panel A) indicate the result from the Gaussian plume model inversion, while the black tracks (panel B) show the boundaries for the integral method.

$F=\sum_{i} V_{i} u \cdot n_{i} \Delta S_{i}$

where $\Delta S_{i}$ is a scalar measure for the length of the boundary segment $i$ under consideration with the normal $n_{i}$. The same wind directions as for the plume inversion have been applied. The boundaries for the method are shown in Fig. 12 for the plume originating from Theodor Shaft and in Fig. 11 for the Bockraden plume.

Potentially the upwind data could be used as a reference. However, in case of Theodor Shaft (Fig. 12), the two nearest upwind tracks show very similar concentrations, but they are both above the regional background (Fig. 13). When inspecting the topography map (see Fig. 1), it can be seen that both these tracks are above the highest surface elevation of this region. Remembering that the retrieval was performed assuming an average surface elevation of $100 \mathrm{~m}$ and taking into account that the actual elevation upwind is considerably higher, this can partly be explained by the retrieval error on the $\mathrm{XCH}_{4}$ result (see Krings et al., 2011, for a detailed sensitivity analysis of the retrieval algorithm). Accumulated over the two upwind tracks, respectively, this results in an enhancement above background comparable to the result of the integral method. Assuming the elevation to be $100 \mathrm{~m}$ higher than used as input for the radiative transfer, more than $80 \%$ of the above background signal can be explained.

The upwind reference data have therefore not been used. Instead, it was assumed that there are no additional $\mathrm{CH}_{4}$ sources of significant strength upwind of the two ventilation shafts.

Downwind cross sections of measurements and plume inversion result are shown in Figs. 14 and 15. Thereby, the model simulations use the same nearest neighbour approach to the cross section tracks to ensure comparability between model and measurements. For Theodor Shaft, the model 
A

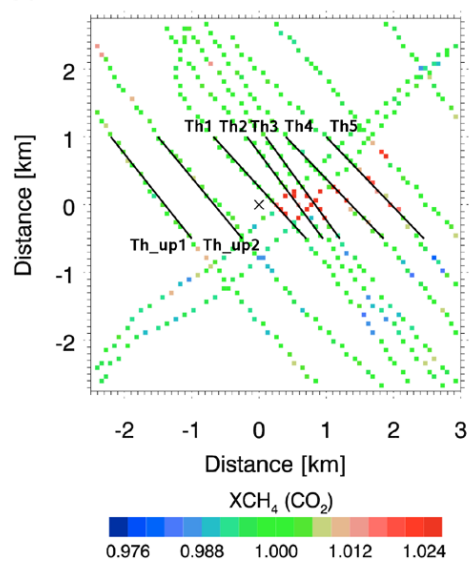

B

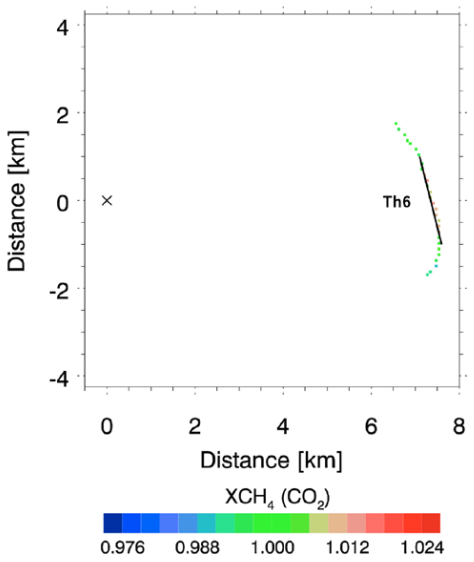

Fig. 12. Boundaries for the integral inversion for near (panel A) and far (panel B) part of Theodor Shaft.

A

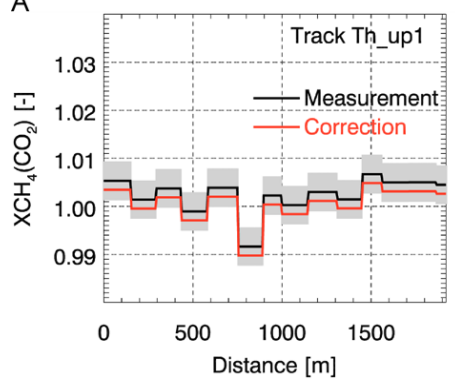

B

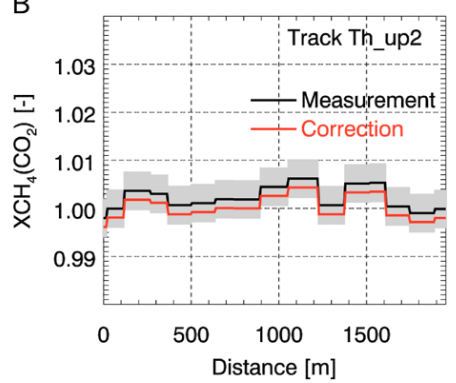

Fig. 13. Measurements along horizontal cross sections upwind of Theodor Shaft (black). Additionally the $1 \sigma$ uncertainty range based on the precision (grey) and a topography correction is shown (red). See Fig. 12 for position of the cross sections.

overestimates the concentrations in the near part, where in the mid-range measurements exceed the model. In the far part, model simulation and measurements have a flat Gaussian shape and agree very well.

In case of Bockraden Shaft (Fig. 15), the furthest measurements agree nicely with the model simulations based on the inversion, whereas, in the mid-part, a change in wind direction with respect to the modelled direction is apparent.

\subsection{Flight pattern and Gaussian integral}

As pointed out by Krings et al. (2011), flight pattern and patchy data can lead to systematic errors for the inversion result of the integral method. Simulations based on the emission rate as resulting from the integral inversion and the stability parameters $a$ obtained from the respective plume fits were performed. The systematic errors for the near and far part of Theodor Shaft and for the Bockraden Shaft are about $-3.8 \%$ (caused by parts of the plume not captured in the lower part (negative y-direction), which cannot be observed for the measurements since the measured plume exhibits a slight bend in positive y-direction), $-4.6 \%$ (plume not completely captured in its horizontal extension) and $-1.2 \%$. The flight pattern error has been corrected for.

\subsection{Results}

Results of the inversion are given in Table 2. The rather large stability parameter of 227.5 for the near part of Theodor Shaft indicates possible additional broadening by changing wind directions or topography, whereas stability for the far part (84.5) and for Bockraden Shaft (120.1) is in the range to be expected for stability class C.

While the integral inversions and the plume inversion of the far part of Theodor Shaft give a rather similar result of about $31 \mathrm{ktCH}_{4} \mathrm{yr}^{-1}$, the plume inversion of the near part indicates a significantly higher emission rate of about $43 \mathrm{ktCH}_{4} \mathrm{yr}^{-1}$ with a much lower statistical error partly due to the higher number of observations that were used.

The inferred emission rate for Bockraden Shaft is significantly lower as could already be expected from a qualitative analysis of the data. The emission estimate from the integral method ( $16 \mathrm{kt} \mathrm{CH}_{4} \mathrm{yr}^{-1}$ ) using 3 tracks is larger than for the plume inversion $\left(12 \mathrm{kt} \mathrm{CH}_{4} \mathrm{yr}^{-1}\right)$. 

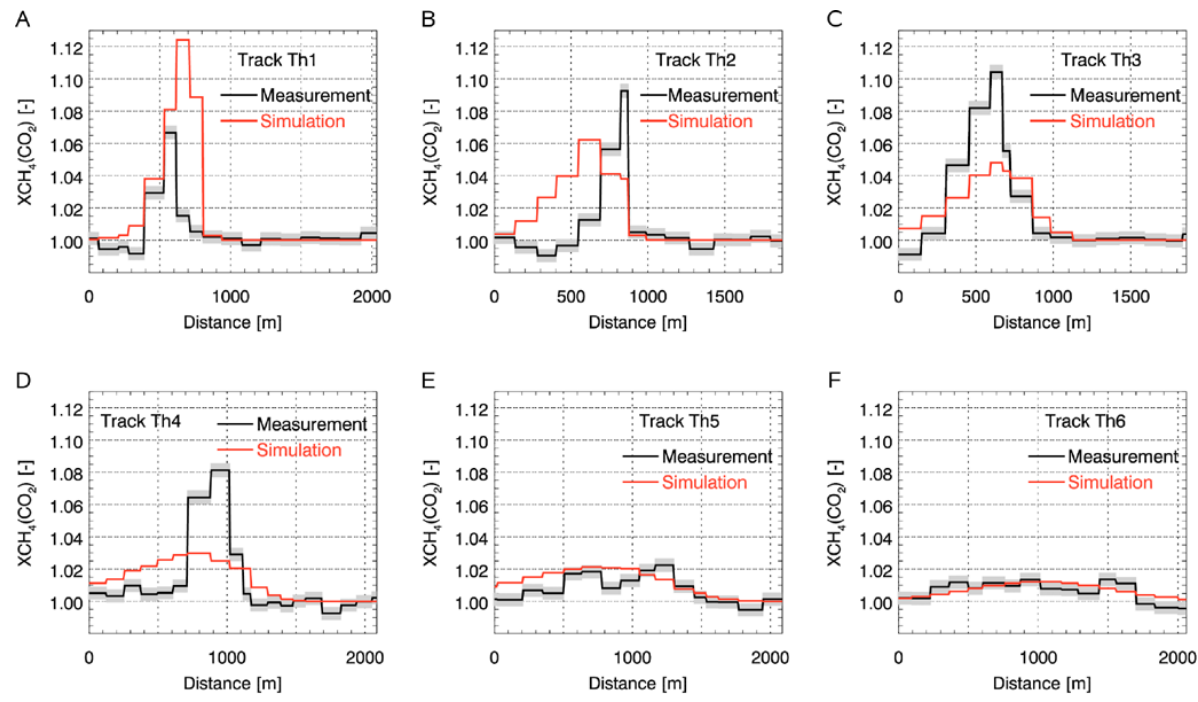

Fig. 14. Measurement (black) with according precision (grey) and plume model simulations (red) using the inversion results along horizontal cross sections through the $\mathrm{CH}_{4}$ plume originating at Theodor Shaft. The position of the cross section tracks is specified in Fig. 12.
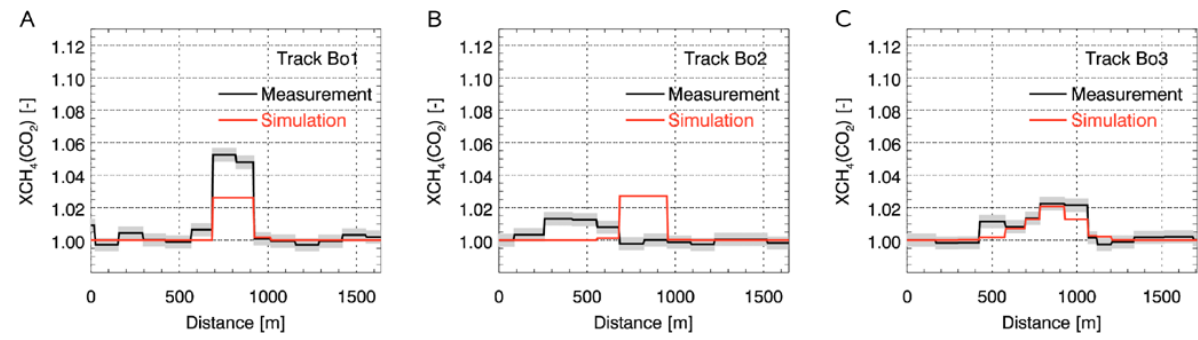

Fig. 15. As Fig. 14 but for Bockraden Shaft. Figure 11 shows the position of the cross sections.

\section{Error discussion}

Several potential sources of error on the inversion are discussed in the following. Aerosol is not assumed to be a major contributor as it already proved to be insignificant for the assessment of emissions from coal-fired power plants where much more aerosol variations are expected (Krings et al., 2011).

\subsection{Effective wind speed and stability}

Not considering the additional $35 \mathrm{~m}$ altitude according to the high-resolution topography from SRTM relative to the COSMO model and just taking the COSMO model elevation $15 \mathrm{~m}$ shaft height for Theodor Shaft results in a $-2 \%$ decreased effective wind speed for both the near and far part of the plume. This gives an indication for the possible magnitude of the uncertainty induced by the topography and its limited representation in the model. The insignificant difference between SRTM and COSMO-DE elevation model of $-8 \mathrm{~m}$ at Bockraden Shaft results only in a negligible variation in effective wind speed. However, Bockraden Shaft is located in a shallow valley, which may have a slight trapping effect on the $\mathrm{CH}_{4}$ plume.

As discussed in Sect. 4, the wind model has been calibrated by measured data, which have an accuracy of about $0.5 \mathrm{~m} \mathrm{~s}^{-1}$. This uncertainty has been adopted for the error estimation, resulting in a relative error of about $8 \%, 7 \%$ and $9 \%$ for the wind speeds in case of Theodor Shaft near $\left(6.2 \mathrm{~m} \mathrm{~s}^{-1}\right)$, Theodor Shaft far $\left(7.0 \mathrm{~m} \mathrm{~s}^{-1}\right)$ and Bockraden Shaft $\left(5.7 \mathrm{~m} \mathrm{~s}^{-1}\right)$. The relative error translates directly into an uncertainty on the inferred emission rate.

\subsection{Wind direction}

The impact on the inversion result originating from uncertainty on the knowledge of the wind direction has been examined by testing wind directions that differ from the assumed wind direction. The knowledge of average wind direction for the far part is assumed to be better $\left( \pm 1.5^{\circ}\right)$ than for the near parts of the plumes $\left( \pm 5^{\circ}\right)$, simply by noting that a changed wind direction leads to a larger spatial displacement in the distance. The different wind directions have been applied to inversion procedures of actual measurements and 
Table 2. $\mathrm{CH}_{4}$ emission rate results in $\mathrm{kt} \mathrm{CH}_{4} \mathrm{yr}^{-1}$ for the coal mine ventilation shafts Theodor Shaft and Bockraden Shaft using the Gaussian plume model and the Gaussian integral inversion methods. For the Gaussian plume model, the result for the retrieved stability parameter $a$ and the statistical errors are also given. The data from Theodor Shaft have been inverted separately for the near and far part of the plume.

\begin{tabular}{|c|c|c|c|c|c|}
\hline \multirow[b]{2}{*}{ Ventilation shaft } & \multicolumn{3}{|c|}{ Plume inversion } & \multicolumn{2}{|c|}{ Integral inversion } \\
\hline & $\begin{array}{l}\text { emission } \\
\left(\mathrm{kt} \mathrm{yr}^{-1}\right)\end{array}$ & $\begin{array}{l}\text { \# pixels used } \\
\text { for inversion }\end{array}$ & $\begin{array}{l}\text { stability } \\
\text { parameter (-) }\end{array}$ & $\begin{array}{l}\text { emission } \\
\left(\mathrm{kt} \mathrm{yr}^{-1}\right)\end{array}$ & $\begin{array}{l}\text { \# tracks used } \\
\text { for inversion }\end{array}$ \\
\hline Theodor Shaft (near) & $\begin{array}{l}43.125 \\
\pm 1.065\end{array}$ & 80 & $\begin{array}{l}227.5 \\
\pm 3.0 \%\end{array}$ & 31.151 & 5 \\
\hline Theodor Shaft (far) & $\begin{array}{l}31.830 \\
\pm 5.233\end{array}$ & 28 & $\begin{array}{l}84.5 \\
\pm 18.8 \%\end{array}$ & 30.819 & 1 \\
\hline Bockraden Shaft & $\begin{array}{l}12.363 \\
\pm 0.419\end{array}$ & 74 & $\begin{array}{l}120.1 \\
\pm 6.8 \%\end{array}$ & 16.088 & 3 \\
\hline
\end{tabular}

Table 3. Error on simulated and measured inversion results due to uncertainty on wind direction.

\begin{tabular}{lcrrrr}
\hline & & \multicolumn{4}{c}{$\Delta$ inversion $(\%)$} \\
\cline { 3 - 6 } Ventilation shaft & $\Delta$ wind & direction $\left({ }^{\circ}\right)$ & \multicolumn{2}{c}{ Simulation } & \multicolumn{2}{c}{ Measurement } \\
& & Plume & Integral & Plume & Integral \\
\hline Theodor (near) & -5.0 & -5.3 & +7.1 & -3.9 & +7.0 \\
& +5.0 & +0.04 & -7.9 & +1.4 & -7.8 \\
Theodor (far) & -1.5 & +0.36 & +0.62 & -5.9 & +0.62 \\
& +1.5 & -0.44 & -0.69 & -1.5 & -0.69 \\
Bockraden & -5.0 & -5.3 & +2.0 & -29.5 & +2.0 \\
& +5.0 & +6.9 & -2.8 & +25.5 & -2.8 \\
\hline
\end{tabular}

simulations (Table 3). The sensitivities vary significantly for different plumes and methods.

For the integral method, when not changing the actual tracks, the modified wind direction impacts only the angle between wind and track normal vector so that the effects for measurement and simulation are essentially equal and are on the order of a few percent.

This is not the case for the plume inversion method, where measurements close to the source may drastically change the result. Here, the plume shape is particularly dependent on changing wind directions. This is less significant in case of the near part of Theodor Shaft, where the first $300 \mathrm{~m}$ of measurements have been omitted. However, this was not done for the sparser methane enhancements at Bockraden Shaft at the expense of a rather large uncertainty with respect to the assumed wind direction.

\subsection{Restriction to relevant measurement area}

For the plume inversion of the near part of Theodor Shaft, influence on the inversion result of the restriction to $\pm 1000 \mathrm{~m}$ in across wind direction is insignificant (less than $0.05 \%$ ) when extended by $1000 \mathrm{~m}$ in each direction. The exclusion of the very near and mid-part of the plume is physically reasonable to avoid short-term wind changes affecting the overall result. However, when the data area for the near part of the plume is reduced by $50 \%(-750 \mathrm{~m})$, the inversion result changes by $+1.7 \%$, and when extended by $50 \%$, the inversion yields $-6.0 \%$ less suffering visibly from changing wind directions. This apparent variability in wind direction leads to the choice of the relevant measurement area in the first place.

In case of the far part of the Theodor plume, extending the across wind direction extension by $+1000 \mathrm{~m}$ in either direction reduces the plume inversion result by about $-1.4 \%$, while extension in along wind direction in either direction does not make sense, since only the furthest track is under investigation.

Also for the Bockraden Shaft, the plume inversion is stable regarding increase of the across wind direction extension by $+1000 \mathrm{~m}$, where no significant change of the inversion result occurs. Extending the range in wind direction by $+500 \mathrm{~m}$ results in a decrease by $-1.3 \%$. This is a very low sensitivity considering the scattering of the plume. When the relevant area is not beginning at the source but at $+300 \mathrm{~m}$ downwind distance from the source, the result is $-4.9 \%$ lower.

For the integral method in case of the near part of Theodor Shaft, extending or shortening at the lower ends of all tracks by $\pm 200 \mathrm{~m}$ in y-direction changes the inversion result by $-5.4 \%$ and $+0.4 \%$ respectively. Extension of the track might potentially be sensitive to the $\mathrm{CO}_{2}$ emissions of the nearby power plant. Extending or shortening at the upper ends of all tracks by $\pm 200 \mathrm{~m}$ in y-direction changes the inversion result by $-0.9 \%$ and $-0.4 \%$, respectively.

The impact of the same procedure on the Bockraden integral result is $+0.8 \%,-0.7 \%,-0.4 \%$, and $-2.2 \%$.

Extending or shortening the integral path for the far part of the plume is not useful, because the straight part of the track is not long enough, and shortening would lead to clear cutting of the plume.

\subsection{Conversion factor, non-linearity and plume height issues}

The uncertainty of the conversion factor has been determined by synthetic retrievals of simulated data taking into account 
also vertical dispersion according to Eq. (2) and assuming slightly unstable conditions (stability class $\mathrm{C}$ ).

The far part inversion is biased by about $-0.5 \%$ for the plume and the integral method. At this distance, the vertical extension of the simulated plume slightly exceeds the aircraft altitude leading to a small underestimation of the source strength.

In case of Bockraden Shaft, the integral inversion is biased by $+0.1 \%$, whereas the plume inversion is biased by $-1 \%$. The negative bias of the plume inversion is due to a relatively large deviation from the true column $(-0.19 \%$ maximum) for measurement pixels close to the source where highest concentrations can be found. This is potentially due to non-linearity effects not considered in the WFM-DOAS algorithm for large deviations from the fixed linearisation point mole fractions. Further away from the source, where methane concentrations are lower, this effect is lower than the effect from the conversion factor that generally slightly overestimates column concentrations when the plume is not equally distributed below the aircraft but lower to the ground.

For the near part of Theodor Shaft, the inversion of the methane columns retrieved from simulated data is biased by $-0.3 \%$ for the plume inversion and integral method relative to the simulated emission rate. The reasons for the negative bias are similar as for Bockraden Shaft. However, by omitting the first $300 \mathrm{~m}$ for the plume inversion, where highest columnar increase can be found, the effect is smaller.

Hence, the overall contribution of these effects to the total uncertainty on the inversion result is rather low in all cases and is in line with results obtained for $\mathrm{CO}_{2}$ inversions by Krings et al. (2011).

\subsection{Uncertainty of the methane background column}

Uncertainties in the assumed background column of methane have direct impact on the inversion result. For this study, the background column has been constrained using the in situ absolutely calibrated data to scale a US Standard profile. The resulting column-averaged dry air mole fraction is about $\mathrm{XCH}_{4}=1757 \mathrm{ppb}$. Assuming a $\pm 1 \%$ uncertainty this gives a range of about 1740-1774 ppb, which is realistic for the area of interest. The resulting uncertainty propagated to the inversion result is then also $\pm 1 \%$.

\section{Comparison with reported data}

To obtain a total emission rate for the mine, a weighted mean has been computed from the individual results. In case of Theodor Shaft, first the mean of the plume inversion results of near and far part weighted by the inverse error, and the mean of the integral method weighted by the number of tracks (see Table 2) has been calculated. The arithmetic mean of both gives the final result for Theodor Shaft (36.155 $\mathrm{kt} \mathrm{CH}_{4} \mathrm{yr}^{-1}$ ), whereas, for Bockraden Shaft, the final result is the arithmetic mean between integral and plume inversion method (14.226 $\mathrm{kt} \mathrm{CH}_{4} \mathrm{yr}^{-1}$ ).

The results have been compared with data as reported by the mine showing an astonishingly good agreement (see Table 4). The difference between the mean inversion model result and the total reported emissions is less than $1 \%$. For the individual shafts, the inversion result is about $4 \%$ lower compared to the reported emissions for Theodor Shaft and about $16 \%$ higher in case of Bockraden Shaft.

\section{Overall inversion errors}

Uncertainties for individual inversion methods and ventilation shafts have been propagated to the individual and total emission rates taking into account the calculation specification for obtaining the weighted mean (Table 5). This is straightforward for the independent statistical error from the plume inversion using Gaussian error propagation. In case of wind direction, the - compared to the simulations - larger variations for the measurements have been considered to give a conservative error estimate. To account for the non-random behaviour in this case, no Gaussian propagation has been applied but a maximum error estimation, that is, a linear accumulation of the absolute values of errors taking into account the largest errors for each shaft and method. This gives a reasonable worst case estimate. The same applies for uncertainties due to wind speed, considered measurement area, conversion factor and topography representation.

By computing the root of the sum of the squared individual, independent errors listed in Table 5, the approximate total uncertainty on the inferred total emission result becomes about $13.5 \%$ and for the individual shafts $13.2 \%$ (Theodor) and $17.2 \%$ (Bockraden). Thereby, the total uncertainty comprises all random and systematic error components. The resulting uncertainties are strongly reduced compared to the power plant experiment by Krings et al. (2011) using the same instrument and inversion techniques. This is predominantly based on the reduced error in wind speed due to calibration with measurements by the AIMMS-20 instrument and generally higher wind speeds in the boundary layer that reduce the relative error. However, uncertainty on wind information still dominates the error budget.

\section{Summary and conclusions}

Airborne passive optical remote sensing data obtained with the MAMAP instrument over two coal mine ventilation shafts were used to retrieve column-averaged dry air mole fractions of methane $\mathrm{XCH}_{4}\left(\mathrm{CO}_{2}\right)$ using the $\mathrm{CO}_{2}$ proxy method. Based on an instrument modification (not subject of this work) suggested by Gerilowski et al. (2011), the instrumental precision could be improved to below $0.4 \%$ for $\mathrm{XCH}_{4}\left(\mathrm{CO}_{2}\right)$. A similar precision or better can now also be reached for $\mathrm{XCO}_{2}\left(\mathrm{CH}_{4}\right)$. 
Table 4. Comparison between reported and inferred $\mathrm{CH}_{4}$ emission rates. For Theodor Shaft, the two lines indicate the near and far part of the plume. The total result refers to the weighted mean of the inversion results according to involved uncertainties. See main text for more information. Reported values have been kindly provided by the district government of Arnsberg (Bezirksregierung Arnsberg, Abteilung Bergbau und Energie in NRW).

\begin{tabular}{lcccc}
\hline & \multicolumn{3}{c}{ Emission rate $\left(\mathrm{ktCH}_{4} \mathrm{yr}^{-1}\right)$} \\
\cline { 2 - 4 } Ventilation shaft & Reported & \multicolumn{3}{c}{ Inversion result } \\
\cline { 3 - 5 } & & Plume inversion & Integral inversion & (Weighted) Mean \\
\hline \multirow{2}{*}{ Theodor Shaft } & 37.690 & $33.125 \pm 1.065$ & 31.151 & 36.155 \\
Bockraden Shaft & 12.274 & $12.363 \pm 0.419$ & 16.088 & 14.226 \\
\hline Total & 49.964 & & 50.381 \\
\hline
\end{tabular}

Table 5. Uncertainties by parameter on the inversion results for the individual ventilation shafts and for the total coal mine.

\begin{tabular}{|c|c|c|c|}
\hline \multirow[b]{2}{*}{ Parameter } & \multicolumn{3}{|c|}{ Uncertainty (\%) } \\
\hline & $\begin{array}{c}\text { Theodor } \\
\text { Shaft }\end{array}$ & $\begin{array}{c}\text { Bockraden } \\
\text { Shaft }\end{array}$ & Total \\
\hline Wind speed $\left( \pm 0.5 \mathrm{~m} \mathrm{~s}^{-1}\right)$ & \pm 7.9 & \pm 8.8 & \pm 8.2 \\
\hline Wind direction $\left( \pm 5^{\circ}\right)$ & \pm 5.2 & \pm 14.4 & \pm 7.8 \\
\hline Statistical error & \pm 7.4 & \pm 2.9 & \pm 5.4 \\
\hline Considered measurement area & \pm 5.0 & \pm 3.4 & \pm 4.6 \\
\hline Topography representation & \pm 2.0 & - & \pm 1.4 \\
\hline $\mathrm{CH}_{4}$ background column $( \pm 1 \%)$ & \pm 1.0 & \pm 1.0 & \pm 1.0 \\
\hline Conversion factor $k$ & \pm 0.5 & \pm 0.5 & \pm 0.5 \\
\hline Total uncertainty & \pm 13.2 & \pm 17.2 & \pm 13.5 \\
\hline
\end{tabular}

During the AIRMETH 2011 aircraft campaign, which, beside the MAMAP instrument, comprised an AIMMS-20 turbulence probe and a fast in situ analyser, an area with two coal mine ventilation shafts was surveyed. Using the same inversion methodologies as Krings et al. (2011) used for the inversion of $\mathrm{CO}_{2}$ emission rates from two coal-fired power plants, namely a Gaussian plume inversion as well as a simple integral approach, methane emissions could be inferred. A significant improvement to the methods could be reached by incorporating wind data of the turbulence probe that were used to calibrate wind data from the analysis runs of the numerical weather prediction model COSMO-DE. The simultaneously recorded in situ data were in good agreement with the MAMAP measurements and could be utilised to refine underlying stability assumptions for the inversion model.

Total mine emissions were estimated to about $50.4 \mathrm{ktCH}_{4} \mathrm{yr}^{-1}$ for the time of the overflight. The error on the inversion result is dominated by uncertainty in wind information, i.e. wind speed and direction, and is about $13.5 \%$ of the inferred emission rate. With deviations of less than $1 \%$, the result is in very good agreement with official emission information provided by the district government for the time of the overflight.
The results confirm that MAMAP is a useful tool to study strong point sources of the greenhouse gases $\mathrm{CO}_{2}$ (Krings et al., 2011) and $\mathrm{CH}_{4}$. The methods developed here are valuable and relevant also to analysis of satellite data with sufficient spatial resolution and precision, such as expected for CarbonSat (Bovensmann et al., 2010).

Acknowledgements. The MAMAP activities are funded in parts by the University of Bremen and the State of Bremen (WFB), the Alfred Wegener Institute for Polar and Marine Research (AWI), Germany and the Helmholtz Centre Potsdam, GFZ German Research Centre for Geosciences, Germany. The Polar 5 aircraft was operated by Kenn Borek Air Ltd, Canada. The official reference values for methane emission rates were kindly provided by the Bezirksregierung Arnsberg, Abteilung Bergbau und Energie in $N R W$. Wind data from the COSMO-DE model were obtained from the German Weather Service (DWD). We thank our reviewers for their helpful comments to improve this article.

Edited by: H. Worden

\section{References}

Babilotte, A., Lagier, T., Fiani, E., and Taramini, V.: Fugitive Methane Emissions from Landfills: Field Comparison of Five Methods on a French Landfill, J. Environ. Eng.-ASCE, 136, 777784, doi:10.1061/(ASCE)EE.1943-7870.0000260, 2010.

Beswick, K. M., Gallagher, M. W., Webb, A. R., Norton, E. G., and Perry, F.: Application of the Aventech AIMMS20AQ airborne probe for turbulence measurements during the Convective Storm Initiation Project, Atmos. Chem. Phys., 8, 5449-5463, doi:10.5194/acp-8-5449-2008, 2008.

Beychok, M. R.: Fundamentals of Stack Gas Dispersion, Milton R. Beychok, 4th Edn., 2005.

Bovensmann, H., Burrows, J. P., Buchwitz, M., Frerick, J., Noël, S., and Rozanov, V. V.: SCIAMACHY: Mission Objectives and Measurement Modes, J. Atmos. Sci., 56, 127-150, 1999.

Bovensmann, H., Buchwitz, M., Burrows, J. P., Reuter, M., Krings, T., Gerilowski, K., Schneising, O., Heymann, J., Tretner, A., and Erzinger, J.: A remote sensing technique for global monitoring of power plant $\mathrm{CO}_{2}$ emissions from space and related applications, 
Atmos. Meas. Tech., 3, 781-811, doi:10.5194/amt-3-781-2010, 2010.

Burrows, J. P., Hölzle, E., Goede, A. P. H., Visser, H., and Fricke, W.: SCIAMACHY-Scanning Imaging Absorption Spectrometer for Atmospheric Chartography, Acta Astronaut., 35, 445-451, 1995.

Doms, G.: A Description of the Nonhydrostatic Regional COSMOModel, Deutscher Wetterdienst, Technical Report, available at: http://www.cosmo-model.org/ (last access: October 2012), 2011.

Dones, R., Bauer, C., and Röder, A.: Kohle, in: Sachbilanzen von Energiesystemen: Grundlagen für den ökologischen Vergleich von Energiesystemen und den Einbezug von Energiesystemen in Ökobilanzen für die Schweiz, Final report ecoinvent No. 6-VI, edited by: Dones, R. et al., Paul Scherrer Institut Villigen, Swiss Centre for Life Cycle Inventories, Dübendorf, CH, 2007.

EnergieAgentur.NRW: Grubengas. Ein Energieträger in NordrheinWestfalen, Ministerium für Wirtschaft, Mittelstand und Energie des Landes Nordrhein-Westfalen, 36 pp., 2009.

Forster, P., Ramaswamy, V., Artaxo, P., Berntsen, T., Betts, R., Fahey, D. W., Haywood, J., Lean, J., Lowe, D. C., Myhre, G., Nganga, J., Prinn, R., Raga, G., Schulz, M., and Dorland, R. V.: Changes in Atmospheric Constituents and in Radiative Forcing, in: Climate Change 2007: The Physical Science Basis. Contribution of Working Group I to the Fourth Assessment Report of the Intergovernmental Panel on Climate Change, edited by: Solomon, S., Qin, D., Manning, M., Chen, Z., Marquis, M., Averyt, K. B., Tignor, M., and Miller, H. L., Cambridge University Press, Cambridge, United Kingdom and New York, NY, USA, 2007.

Frankenberg, C., Meirink, J. F., van Weele, M., Platt, U., and Wagner, T.: Assessing Methane Emissions from Global Space-Borne Observations, Science, 308, 1010-1014, doi:10.1126/science.1106644, 2005.

Gaft, M., Reisfeld, R., and Panczer, G.: Modern Luminescence Spectroscopy of Minerals and Materials, 368 pp., SpringerVerlag, Berlin, Heidelberg, 2005.

Gerilowski, K., Tretner, A., Krings, T., Buchwitz, M., Bertagnolio, P. P., Belemezov, F., Erzinger, J., Burrows, J. P., and Bovensmann, H.: MAMAP - a new spectrometer system for columnaveraged methane and carbon dioxide observations from aircraft: instrument description and performance analysis, Atmos. Meas. Tech., 4, 215-243, doi:10.5194/amt-4-215-2011, 2011.
Hess, M., Koepke, P., and Schult, I.: Optical Properties of Aerosols and Clouds: The Software Package OPAC, B. Am. Meteorol. Soc., 79, 831-844, doi:10.1175/15200477(1998)079<0831:OPOAAC>2.0.CO;2, 1998.

Hunt, J. C. R. and Snyder, W. H.: Experiments on stably and neutrally stratified flow over a model three-dimensional hill, J. Fluid Mech., 96, 671-704, doi:10.1017/S0022112080002303, 1982.

Krings, T., Gerilowski, K., Buchwitz, M., Reuter, M., Tretner, A., Erzinger, J., Heinze, D., Pflüger, U., Burrows, J. P., and Bovensmann, H.: MAMAP - a new spectrometer system for columnaveraged methane and carbon dioxide observations from aircraft: retrieval algorithm and first inversions for point source emission rates, Atmos. Meas. Tech., 4, 1735-1758, doi:10.5194/amt-41735-2011, 2011.

Martin, D. O.: The Change of Concentration Standard Deviations with Distance, J. Air Poll. Control Assoc., 26, 145-147, doi:10.1080/00022470.1976.10470238, 1976.

Pasquill, F.: Atmospheric dispersion of pollution, Q. J. Roy. Meteor. Soc., 97, 369-395, doi:10.1002/qj.49709741402, 1971.

Rozanov, A., Rozanov, V., Buchwitz, M., Kokhanovsky, A., and Burrows, J. P.: SCIATRAN 2.0 - A new radiative transfer model for geophysical applications in the $175-2400 \mathrm{~nm}$ spectral region, Adv. Space. Res., 36, 1015-1019, doi:10.1016/j.asr.2005.03.012, 2005.

Schneising, O., Buchwitz, M., Burrows, J. P., Bovensmann, H., Bergamaschi, P., and Peters, W.: Three years of greenhouse gas column-averaged dry air mole fractions retrieved from satellite - Part 2: Methane, Atmos. Chem. Phys., 9, 443-465, doi:10.5194/acp-9-443-2009, 2009.

Schneising, O., Buchwitz, M., Reuter, M., Heymann, J., Bovensmann, H., and Burrows, J. P.: Long-term analysis of carbon dioxide and methane column-averaged mole fractions retrieved from SCIAMACHY, Atmos. Chem. Phys., 11, 2863 2880, doi:10.5194/acp-11-2863-2011, 2011.

Shindell, D. T., Faluvegi, G., Koch, D. M., Schmidt, G. A., Unger, N., and Bauer, S. E.: Improved Attribution of Climate Forcing to Emissions, Science, 326, 716-718, doi:10.1126/science.1174760, 2009.

Turner, D. B.: Workbook of Atmospheric Dispersion Estimates, US Department of Health, Education, and Welfare, 95 pp., 1970.

Wuebbles, D. J. and Hayhoe, K.: Atmospheric methane and global change, Earth-Sci. Rev., 57, 177-210, doi:10.1016/S00128252(01)00062-9, 2002. 